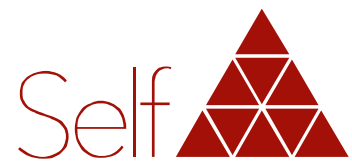

Revista do Instituto Junguiano de Säo Paulo

\title{
A escuta da clínica analítica ${ }^{1}$
}

\author{
Paula PERRONE
}

São Paulo, SP, Brasil.

\section{Resumo}

O artigo trata do uso da história de vida em uma pesquisa da autora sobre o processo de individuação. Na análise e na pesquisa, a história de vida é o método que favorece a escuta e ele pode ser enriquecido pela antropologia e pela psicologia profunda. Rousseau concebeu a etnologia no século XVIII por ter o outro como motivo primeiro de sua teoria. A "pitié" permite sua identificação com o sofrimento de seu semelhante. Merleau-Ponty se voltou para a antropologia pela sua maneira de pensar quando o objeto é o "outro" e exige nossa transformação. Criamos interfaces entre a antropologia e a psicologia analítica, uma vez que alteridade é a questão junguiana. Jung avalia como condição necessária para o verdadeiro encontro o exercício consciente da retirada das projeções sobre o mundo externo. Segunda interface: a escuta analítica. Ela procura alcançar as fantasias inconscientes e facilitar que camadas inconscientes aflorem. Para Merleau-Ponty a percepção é seletiva. A escuta da psicologia profunda é seletiva, perspectivista. Terceira interface: a experiência da intersubjetividade. O campo interativo entre o narrador e o ouvinte de uma história de vida pode comportar a constituição de um terceiro elemento, produto do encontro das duas subjetividades: o corpo sutil. Nessa sintonia, falamos de acordo com esse campo de sensibilidade constituída. A clínica também está presente quando se estuda com alunos ou na pesquisa em ciências humanas

Conflito de interesses: A autora declara não haver nenhum interesse profissional ou pessoal que possa gerar conflito de interesses em relação a este manuscrito. a partir de narrativas. Tem uma função no mundo, pode produzir uma metodologia refinada. A fala de meu entrevistado pertence ao domínio do "terceiro incluído". Jung explicou profundamente essa cópula simbólica.

\section{Descritores}

escuta analítica, alteridade, psicologia junguiana.

Recebido: 11 nov 2016; $1^{\text {a }}$ revisão: 30 nov 2016; Aprovado: 09 jan 2017; Aprovado para publicação: 16 mar 2017. 


\title{
Listening in the analytical clinic
}

\begin{abstract}
This article deals with the use of a life story in the author's research on the individuality process. In analysis and research, the life story is the method that favors listening. Anthropology and deep psychology can enrich it. Rousseau conceived of ethnology in the XVIII century with the other as the main motive of the theory. The "pitié" allows for identification with the suffering of fellow man. Merleau-Ponty considered anthropology through its way of thinking when the object is the "other" and demands our transformation. We have created interfaces between anthropology and analytical psychology, because otherness is the Jungian matter. Jung evaluates the conscious exercise of withdrawing from any projection of the external world as a necessary condition for a true encounter. Second interface: analytical listening. It seeks to reach the unconscious fantasies and to facilitate the rising up of unconscious layers. For Merleau-Ponty, the perception is selective, perspectivist, like deep psychology listening. Third interface: the experience of the intersubjectivity. The interactive field between the storyteller and the listener of a life story bears a third element, the product of the encounter between the two subjectivities: the subtle body. In this harmony, we speak according to this constituted field of sensitivity. The clinic is also present in study with students, or in human sciences research, based on narratives. It has a role in the world and can produce a refined methodology. The words of my interviewee belong to the domain of the "third included". Jung deeply expounded on this symbolic copulation.
\end{abstract}

\section{Descriptors}

psychoanalytical listening, alterity, Junguian psychology. 


\section{La escucha de la clínica analítica}

\section{Resumen}

El artículo trata sobre la utilización de la historia de vida en una investigación, hecha por la autora, sobre el proceso de individuación. En el análisis y en la investigación la historia de vida es el método que favorece la escucha. La antropología y la psicología profunda pueden enriquecerla. Rousseau concibió la etnología en el siglo XVIII por tener al otro como principal razón de su teoría. La "pitié" permite la identificación con el sufrimiento de su semejante. Merleau-Ponty pensó la antropología por su forma de pensar cuando el objeto es el "Otro" y requiere nuestra transformación. Creamos interfaces entre la antropología y la psicología analítica porque la alteridad es una cuestión Junguiana. Jung evalúa que el ejercicio consciente de la retirada de las proyecciones sobre el mundo exterior es condición necesaria para el verdadero encuentro. Segunda interfaz: la escucha analítica que busca alcanzar las fantasías inconscientes y facilitar que las capas inconscientes salgan a la superficie. Para MerleauPonty la percepción es selectiva. La escucha de la psicología profunda es selectiva, de perspectiva. Tercera interfaz: la experiencia de la intersubjetividad. El campo interactivo entre el narrador y el oyente de una historia de vida puede implicar la creación de un tercer elemento, producto del encuentro de las dos subjetividades: el cuerpo sutil. En este sentido, hablamos de acuerdo con ese campo de sensibilidad constituida. La clínica también está presente cuando se estudia con los alumnos, o en la investigación en humanidades, a partir de narrativas. Tiene una función en el mundo, puede producir una metodología refinada. El discurso de mi entrevistado pertenece al dominio del "tercer incluido". Jung explicó profundamente esta cópula simbólica.

\section{Descriptores}

escucha psicoanalitica, alteridad, psicologia Junguiana. 


\section{Introdução}

Anos atrás concluí uma pesquisa (Perrone, 2003) a respeito do processo de individuação, a partir de duas histórias de vida. Trabalhei com pessoas que tinham um longo caminho percorrido: uma mulher de 79 anos e um homem de 88 anos. Tivemos diversos encontros. $\bigcirc$ universo descortinado pela pesquisa envolvia as noções de narrativa e de experiência, formuladas por Walter Benjamin (1994). Utilizei então uma metodologia das ciências sociais para o emprego da comunicação oral como fonte de conhecimento, uma vez que a sociologia partidária das técnicas qualitativas de pesquisa considera a narrativa o meio mais rico para obtenção de dados. A sistematização da metodologia de coleta de dados através da comunicação oral foi elaborada por Maria Isaura P. Queiroz (1988), que diferenciou os tipos de relato.

Para Queiroz (1988), em um depoimento interessa uma só esfera da vida do sujeito, e o que conta é que ele atesta algo conhecido ou vivido. Geralmente, o depoimento não é extenso. Já a entrevista se volta para determinado tema previamente definido pelo pesquisador, que também pauta a conversa e, portanto, as informações fornecidas. A entrevista pode ser aberta, semiaberta ou fechada. Sua interface com o terceiro tipo de relato, a história de vida, baseia-se no fato de que a entrevista pressupõe um prolongamento do encontro entre entrevistador e entrevistado, além de que o conteúdo visado encontra-se no âmbito da história de vida do entrevistado.

Nos Estados Unidos há muito tempo a história de vida já era empregada como metodologia qualitativa, em função do desaparecimento de tribos indígenas, com o intuito de conservar a lembrança de sua organização e costumes; o mesmo acontecia na Europa, principalmente na França, desde o século XIX, em pesquisas sobre o modo de vida camponês, visando a registrar sua maneira de agir e pensar. No Brasil, somente apareceu como instrumento de pesquisa na metade do século XX, mas foi preterida em função do encantamento com as técnicas estatísticas; também foi considerada subjetiva pelos cientistas, que temiam serem levados a interpretações errôneas a partir dos dados fornecidos pelos sujeitos. Há mais de duas décadas, todavia, o relato reapareceu sob o nome de "história oral", ocupando lugar privilegiado enquanto técnica de coleta de material empregada pelos cientistas sociais.

Segundo o historiador José Carlos Bom Meihy (1998), na história oral de vida, a subjetividade predomina sobre a objetividade e justamente aí reside sua força. Davi Arrigucci Junior (1987), crítico literário, também discute o trabalho do narrador. Vê a pesquisa como um percurso de busca que demanda uma entrega do pesquisador ao material coletado e, ao trabalhar em uma perspectiva qualitativa, é preciso fazer emergir o encoberto, trazer à tona o obscuro, o desconhecido. Refere-se à dimensão menos lógica do que poética, como enriquecimento e ampliação do âmbito da ciência. Para tanto, segundo ele, o pesquisador deve silenciar a fim de ouvir o sujeito e 
permitir que ele se configure a sua frente, assim como para estabelecer os recortes de sua interpretação. Nós, psicólogos, temos no outro e, portanto, na história de vida do outro, o nosso objeto de trabalho e, na subjetividade, nossa matéria. Jung via na subjetividade o ponto de partida para atingir a objetividade. Na subjetividade reside o valor da história de vida para a pesquisa ou para a clínica psicológica.

trabalho de pesquisa contou com uma escuta analítica, abordagem na qual desenvolvo minha clínica psicológica, já que sou analista junguiana por profissão. Antes de introduzir esta questão parece oportuno lembrar porque a palavra e a escuta se tornaram importantes na psicanálise. Nas sociedades ditas "primitivas" e nas sociedades tradicionais pré-capitalistas, as relações de parentesco ou outros critérios sociais praticados situavam os homens nas trocas sociais e asseguravam-lhes um lugar e um valor no contexto social, cujas regras coletivas eram claramente estabelecidas e às quais eles se submetiam sem que com isso houvesse envolvimento de sua subjetividade. Bem diferente é a situação do sujeito moderno que, despojado desses tipos de relações socioculturais onde se localiza e pelas quais se orienta, tem que arcar, em sua psique, com o que antes era desempenhado pelas formações sociais, ou seja, com o que está fora dele. $O$ sujeito moderno está destinado a construir-se a si mesmo. A partir do final do século XIX a escuta da psicanálise veio trazer as ferramentas para que ele pratique a escuta de si. Quando Freud deixa para trás as técnicas da hipnose e da sugestão, ele o faz por reconhecer-lhes a ineficácia terapêutica, pois os conteúdos revelados não eram integrados à consciência do doente, embora fornecessem pistas etiológicas ao médico. A convocação por parte do analista da fala por associação livre produziu uma valorização da fala do analisando. A partir daí, ele é conduzido a aproximar-se de sua dimensão inconsciente, da qual esteve alijado até então. A demanda para que a palavra do analisando seja - veículo de seu autoconhecimento deslocou para o paciente a "responsabilidade" do tratamento, a partir do que ele diz, de acordo com a regra combinada. Obriga-se a comunicar tudo o que percebe, mesmo que sem sentido ou conexão com o que é tratado, sem nenhuma coerção, com total liberdade. Com esse ponto de partida Freud desenvolveu seus estudos sobre a resistência, decidindo por interpretá-la, situá-la no terreno da transferência, que considerou o núcleo e a mola propulsora do tratamento analítico e propondo sua fundação e resolução junto ao analisando. Dar a palavra para o outro e ficar em uma posição passiva de escuta foi um ato revolucionário. Esse movimento, por si, propicia uma revelação.

Pela sua própria natureza, a história de vida, enquanto material de pesquisa, pede do narrador e do ouvinte uma postura cuidadosa. Uma história de vida tem um caráter definitivo; mesmo que se transforme, não há como apagar o vivido. Ela encerra o que de mais forte um indivíduo tem para compartilhar: sua experiência e sua personalidade, fortemente enlaçadas, praticamente traduzidas no que Jung chamou de destino. Estar diante de material de tal magnitude é bem diferente de colher um depoimento a respeito de alguma área específica da experiência do sujeito. Não se trata de uma entrevista 
qualquer. As duas partes envolvidas de algum modo sabem que o que têm nas mãos está prenhe de subjetividade. Aí está o que governa a postura do ouvinte. $\bigcirc$ que faz esse cuidado ser necessário não é o conteúdo daquela vida narrada, mas o significado que qualquer história de vida tem para quem a vive. Ora, essa escuta aproxima-se em muito da escuta clínica, onde a subjetividade é a matéria-prima, enquanto o narrado é a história de vida.

Durante os encontros com cada um dos sujeitos da pesquisa, no transcorrer das entrevistas, configurou-se entre nós uma atmosfera de magia. A narrativa era feita com emoção e com sentimento; isso me envolvia e tornava minha escuta acurada e profunda. Estávamos percorrendo um caminho juntos, novo para os dois, onde o que havia de conhecido eram os fatos trazidos pelo narrador. Mas o que experimentávamos naqueles momentos, a importância deles para cada um de nós, bem como, em muitos casos, a significação do que era narrado, se construía a cada passo e não sabíamos onde desembocaria. Ambos estávamos vivamente interessados no que fazíamos e, pelo modo como me senti, empreendendo um voo através de uma dimensão desconhecida e envolvente, soube que algo equivalente também se passava com meu entrevistado. Havia troca, confiança e acolhimento. Nessas ocasiões, eu soube também que não havia diferença entre clínica e pesquisa, pois os elementos fundamentais da clínica estavam presentes. Nossa interação era fruto do encontro entre nossas subjetividades. Pisávamos o terreno sagrado da intersubjetividade.

Envolvi-me com as imagens produzidas pelos narradores em nossos encontros e posteriormente as interpretei ao redigir uma dissertação, elaborada por meio de um recorte da teoria junguiana. Trabalhei com a teoria dos complexos, a de tipo psicológico e com o processo de individuação, atendendo ao que, aos meus olhos, o material pedia, ou seja, a partir do que as imagens me suscitaram. Enfim, de todo material coletado, colhi as fantasias, fiquei com a experiência, que frequentemente não pertence ao registro da consciência, fruto que é da memória involuntária, conceito bergsoniano conhecidamente explorado por Proust.

Durante a pesquisa, percebi que a história de vida, método oriundo das ciências sociais, poderia ser enriquecida na interface de duas outras ciências: a psicologia profunda e a antropologia. Com a psicologia profunda, o método de história de vida se alargaria a partir da dimensão da escuta e do terceiro analítico. Com a antropologia, a história de vida poderia ser enriquecida por meio da noção de alteridade.

De acordo com Lévi-Strauss (1989), Rousseau fundou as ciências humanas, quando concebeu e anunciou a etnologia, um século antes que ela surgisse, ao eleger os homens e os costumes de outras regiões como objetos privilegiados de estudo. Ele construiu o lugar do outro e da alteridade, como motivo primeiro de sua teoria, na segunda metade do século XVIII. Rousseau descobriu a necessidade da recusa de si mesmo como condição para a aceitação de seu diferente, melhor dizendo, de seu semelhante. É passando pelo reconhecimento de que "eu é um outro" que se pode descobrir que o 
outro é um eu. A peça-chave de sua teoria, a pitié, é a empatia pelo seu semelhante sem sair do lugar, transportando-se para fora de si mesmo. A pitié é uma paixão natural que pertence ao homem no estado de natureza, uma capacidade inata que permite a identificação com o sofrimento de seu semelhante através do transporte da imaginação. Esse mecanismo de chegar tão próximo do outro vai se obscurecendo no decorrer da civilização, a pitié se enfraquece e o sofrimento do outro já não toca o homem civilizado. Processa-se no homem uma degeneração, instaura-se o amor-próprio e o narcisismo explode: incapaz de compaixão, o homem só vê a si mesmo. Portanto a psicologia profunda deve a esse mestre da natureza e das relações humanas a origem da noção de alteridade e a de seu quase oposto, o narcisismo.

Merleau-Ponty (1980) também pensou a antropologia e afirmou que ela não se constitui em uma especialidade definida por um objeto particular - as sociedades "primitivas" -, mas pela sua maneira de pensar que se impõe quando o objeto é o "outro" e que exige nossa própria transformação. Como diz Merleau-Ponty (1980), nos tornamos etnólogos de nossa própria sociedade se tomamos distância em relação a ela. Nas suas palavras, a antropologia tem um método singular: "Trata-se de aprender a ver o que é nosso como se fôssemos estrangeiros e como se fosse nosso o que é estrangeiro". Ensina Merleau-Ponty (1980) que tomando a alteridade como objeto, a razão sofre um alargamento e se torna capaz de compreender aquilo que antecede e excede a simples razão, pois é obrigada a conviver com incompatíveis; trata-se de instalar-se em um espaço comum onde ambos, nós e os outros, sejamos inteligíveis. Fora da esfera da temerária redução ou transposição, esse espaço emerge quando presidido pela função simbólica que "encontra o real adiantando-o no imaginário". Se a psicanálise e a psicologia analítica pretendem alcançar o mundo, é preciso ter presente esse olhar antropológico que cria distância, que trata o que é estrangeiro como se fosse nosso e o que é nosso como se fosse estrangeiro, isto é, a identificação com o outro pede a desidentificação consigo mesmo. É nesse sentido que podemos aproximar ou criar interfaces entre a antropologia e a psicologia profunda. A antropologia, na leitura merleaupontyana, surge como um subsolo de todas as ciências humanas e como instrumento de uma racionalidade alargada.

Nem é necessário construir esta aproximação no caso da psicologia analítica, pois alteridade é a questão junguiana; para ser alcançada demanda a retirada da projeção das próprias fantasias sobre o mundo externo. Jung avalia como condição necessária para um verdadeiro encontro com o outro o exercício consciente e permanente de retirada das projeções, sem $\circ$ que o indivíduo não é capaz de enxergar ninguém em sua individualidade. Nesse núcleo de sua teoria, Jung está muito próximo de Rousseau, para quem o sujeito é capaz de ocultar o mundo através de véus. A démarche dos dois pensadores é a retirada dos véus. A partir daí tem-se a objetividade do mundo ou o que se pode imaginar como verdade do sujeito, 
na medida em que ele reintegra sua personalidade dirigida para fora até então.

A escuta analítica é outro ponto possível de interface entre a técnica de história de vida e a psicologia profunda. Na escuta analítica, nas psicologias profundas e nas psicanálises o analisando fala " $a$ " e nós escutamos " $a$ " mais "b" ou "b". Nessa dupla escuta, tentamos alcançar as fantasias inconscientes. O movimento é sempre duplo e a meta é criar um facilitador para as camadas inconscientes aflorarem. É sempre um duplo olhar, uma dupla escuta; tentamos capturar o que não é dito. Por que fazemos isso? Porque se pressupõe que o analista foi analisado e aprendeu a fazer a dupla escuta uma vez que reconhece as bases de fundação da palavra e da consciência em outro lugar. Para a psicanálise e para a psicologia analítica, mas especialmente para esta última, a escuta não se restringe ao indivíduo, porém, também é a "escuta da espécie". A história dos complexos é a história dos complexos familiares, através das gerações. A história dos arquétipos é a história da humanidade.

Em seu livro "A fenomenologia da percepção", Merleau-Ponty (1971) afirma que olhamos tudo que está diante de nós, mas não vemos tudo. A visão é seletiva, pois para ver temos que focar o olhar. Vemos algo particular em meio a tudo que é olhado. Uma coisa é olhar, outra coisa é ver. Você olha, mas vê o que? A percepção é seletiva. Da mesma forma podemos pensar a escuta da psicologia profunda. Ouvimos tudo, mas só escutamos o que podemos escutar. Ou seja: só escutamos aquilo que nosso quadro mental nos permite escutar. Merleau-Ponty (1971) insiste no perspectivismo, quando demonstra que toda percepção é seletiva. A percepção depende então do ponto de vista, da perspectiva, do vértice, do quadro mental. A escuta das psicologias profundas é, também, perspectivista. Ao ter incluído no método de história de vida o olhar antropológico que cultiva o outro e a escuta perspectivista da psicologia profunda, espero ter trazido o alcance desse método e apresentado como ele pode se ampliar em si mesmo. Pensemos pelo avesso: o que é pesquisar o social, sem se preocupar com a distância? $\bigcirc$ que significa fazer uma pesquisa de história de vida sem estar consciente da seleção da escuta? Se não vemos o outro, o mundo, como diferentes de nós, não corremos o risco de projetar nossos conteúdos e fantasias sobre eles? Escutamos o que podemos, o que nossa perspectiva permite, desalojando o universal.

Enfim chegamos à terceira interface entre a técnica de história de vida e as psicologias profundas: a experiência da intersubjetividade. Na relação entre narrador e ouvinte de uma história de vida forma-se um campo interativo que pode comportar a constituição de um terceiro elemento, produto da relação das duas subjetividades presentes, o terceiro analítico, como é chamado pela psicanálise, ou corpo sutil, pela psicologia analítica. Ele é criado pelo encontro dos dois indivíduos em um contexto de escuta clínica, que se dá no vértice do passado e do presente e permite a recriação do passado ou a criação de novas possibilidades, um sentido prospectivo. Quando se constela a sintonia do corpo sutil falamos aquilo que jamais 
pensamos, de acordo com esse campo de sensibilidade constituída. A clínica é ampla. Quando se estuda com um grupo de alunos, se faz clínica, os caminhos surgem. Quando se faz pesquisa em psicologia, em ciências sociais, em pedagogia, em antropologia, em arquitetura, na área das ciências humanas em geral, a partir de narrativas, se faz clínica.

A clínica tem uma função no mundo, pode produzir uma metodologia refinada. Se faz clínica no sentido amplo porque o analista, a pessoa que é analisada, manterá em todas as circunstâncias um duplo olhar, uma dupla escuta. Sempre que se trabalha voltado para a compreensão do outro, recria-se o sentido mais profundo da clínica que é o de se inclinar, de cuidar. Se vou fazer uma entrevista sociológica, preciso saber que a fala do meu entrevistado não é casual. Ela configura o domínio intermediário, o domínio do "entre" ou do "terceiro incluído". Segundo Rezende e Gerber (2001), o primeiro contexto da intersubjetividade é o de inclusão das projeções, ou de identificação projetiva. É o surgimento de um primeiro nós, misturado, confuso. O segundo contexto é o da elaboração e transformação do que foi projetado, que restitui a identidade de cada um e institui a verdade como experiência emocional compartilhada. A verdade na relação é a ética, como verdade da convivência, onde a presença do outro ajuda cada um a ser ele mesmo, pois cria oportunidades de serem dadas respostas constituintes das suas personalidades. É ainda possível reconhecer um terceiro contexto, a presença de um nós transcendente a ambos, de tal sorte que ambos de fato se coloquem sob o vértice de "nós", ou a síntese de "eu" e "tu". No vértice do terceiro incluído, os contrários se juntam sem se anularem. Neste terceiro "nós", transubjetivo, a expansão comunicativa se institui. A experiência analítica da intersubjetividade encontra aí seu grande desafio.

Essa cópula simbólica não foi melhor explicada do que por Jung (1999) em "A psicologia da transferência". Na abordagem junguiana também aparecem os três "nós": no primeiro momento com Mercúrio - a massa escura e viva, fruto do encontro analítico; no segundo momento, com as imagens da cópula sexual dos irmãos alquímicos; e no terceiro momento, com a criança como fruto da cópula que, neste caso, é o próprio discurso. Jung escolheu Mercúrio, mensageiro entre diferentes universos, aquele que por meio de sua natureza paradoxal ou duplex é capaz de revelar, traduzir e ligar, para se referir ao milagre da experiência analítica, em que coexistem e convergem não só deuses e homens, mas feminino e masculino, consciência e inconsciência, psique e matéria. Em "A psicologia da transferência" (Jung, 1999) lemos o mergulho profundo presente no terceiro elemento criado a partir do campo constituído no encontro analítico, em que tanto para o paciente como para $\circ$ analista $\circ$ trajeto e $\circ$ ponto de chegada são desconhecidos - e só revelados pelas sugestivas imagens alquímicas, todas elas sob a égide de Mercúrio. O terceiro parceiro é a dimensão do desconhecido ou, conforme Jung, da psique objetiva.

C corpo sutil que, no dizer do analista junguiano Nathan Schwartz-Salant (1997) é produto do campo interativo, pode ser vivenciado no âmbito 
imaginal como uma espécie de campo energético que se expande a partir de nosso ser físico. Schwartz-Salant (1997) identifica três estados de interação dos corpos sutis no contexto de duas pessoas em terapia: podem se manifestar em um estado de fusão, de separação ou ambos podem atuar um sobre o outro na coniunctio. Para esse analista e autor, descobrir e se relacionar imaginalmente com um processo inconsciente e autônomo que cative o terapeuta e o paciente é um meio que o terapeuta tem de ajudar o paciente a vivenciar o numinoso.

A questão não é se o corpo sutil existe ou não, mas se sua existência pode ser percebida ou não, pois quando lidamos com o corpo sutil não estamos interessados em percepções comuns, mas em percepções imaginais. Os que podem ver verão; os que não podem se manterão céticos. (p. 163)

Corpo sutil também pode estar presente em uma entrevista de pesquisa e as psicologias profundas trazem o cuidado necessário alertando para os perigos de projeção, fusão, identificação projetiva. $\bigcirc$ corpo sutil ou terceiro analítico é um lugar de produção de conhecimento relativamente novo, que está sendo trabalhado como tendo um estatuto próprio.

Em "O milagre da conversa", posfácio que fecha um livro sobre a alma brasileira, produzido a partir de uma narrativa na qual ele é o narrador, Dias e Gambini (1999) atestam a presença do terceiro incluído, experiência possível a partir de uma interação intersubjetiva, ou relação simbólica propriamente dita.

Só que não foram encontros de mesa de bar, porque minha experiência durante esses encontros foi a de perceber que uma conversa pode ser um milagre, e quero dizer com isso exatamente o seguinte: quando Eros rege uma interação, há um momento em que se cria uma tal faixa de sintonia e sensibilidade que as perguntas que Lucy me fazia tinham por efeito fazer-me dizer coisas que eu não havia jamais dito ou explicitamente formulado. Eu me sentia descobrindo à medida que refletia, as ideias brotavam como água e fluíam sem interrupção, estimuladas pelas intervenções dela e por um ordenamento interno que eu não supunha estar presente de modo tão imperioso. Não houve uma única vez em que nos sentíssemos perdidos, ou sem ter o que dizer, ou tendo que parar para consultar textos ou anotações. Uma conversa centrada, orientada para uma busca significativa, tem esse maravilhoso poder de abstrair o tempo, as distrações, os segundos pensamentos, e fazer surgir exatamente aquilo que parece ter um desejo próprio de se transformar em palavra. Mesmo que eu estivesse cansado após uma semana intensa de trabalho no consultório, bastava iniciarmos nossas conversas para que de repente eu me sentisse cheio de energia, entusiasmo e eloquência. (pp. 222-223) 
Caminho para se chegar a algum lugar é o método (ódos), é como se faz um trabalho, a eleição de certos meios, a partir de certa perspectiva, como a que se refere à postura do pesquisador diante do narrador ou do analista diante de seu paciente no consultório. Para reavivar a alma do mundo, bem como para desenvolver uma reflexão crítica é importante ter um método, escutar e perceber o mundo do modo como o analista escuta e percebe seu paciente.

\section{Referências}

Arrigucci Junior, D. (1987). Enigma e comentário: escritos sobre literatura e experiências. São Paulo: Companhia das Letras.

Benjamin, Walter.(1994). O narrador. Considerações sobre a obra de Nikolai Leskov. In Obras escolhidas. Magia e técnica, arte e política (pp.197-221). São Paulo: Brasiliense.

Bom Meihy, J. C. (1998). Manual de história oral. São Paulo: Loyola.

Dias, L. \& Gambini, R. (1999). Posfácio. In Outros 500: uma conversa sobre a alma brasileira. São Paulo: Ed. SENAC.

Jung, C. G. (1999). Ab-reação, análise dos sonhos, transferência. In Obras Completas (vol. XVI/2). Petrópolis: Vozes.

Lévi-Strauss, C. (1989). Antropologia estrutural dois. Rio de Janeiro: Tempo Brasileiro.

Merleau-Ponty, M. (1971). A fenomenologia da percepção. Rio de Janeiro, Editora Livraria Freitas Bastos.

Merleau-Ponty, M. (1980). De Mauss a Claude Lévi-Strauss. In Os pensadores (M. Chauí, trad.) (pp. 200). São Paulo: Abril Cultural.

Perrone, P. (2003). Existências fascinadas: história de vida e individuação. São Paulo, Annablume-FAPESP.

Queiroz, M. I. P. (1988). Relatos orais: do "indizível" ao "dizível". In Von Simson, Olga de Moraes (Coord.), Experimentos com histórias de vida. São Paulo: Vértice. A psicanálise "atual" na interface das "novas" ciências (pp. 207-232). São Paulo: Via Lettera

Schwartz-Salant, N. (1997). O corpo sutil e as experiências imaginais no campo interativo (cap. 5, pp. 161-192). In A personalidade limítrofe: visão e cura. São Paulo: Cultrix. 
Minicurrículo: Paula Perrone - Analista junguiana, membro didata da Associação Junguiana do Brasil (AJB) e International Association for Analytical Psychology (IAAP). Doutora e mestre pelo Instituto de Psicologia da Universidade de São Paulo (IPUSP). Membro do corpo docente do Curso de Especialização em Psicologia Analítica Junguiana pela Universidade Estadual de Campinas (Unicamp). Diretora do Instituto Junguiano de São Paulo (IJUSP AJB 2016-18). Autora de diversos artigos e do livro "Existências fascinadas: história de vida e individuação" (São Paulo, Annablume/Fapesp, 2003). Email: paulaperrone1@gmail.com

\footnotetext{
'Perrone, M. P. (2002). A clínica do social: escuta e alteridade. In Cínicas arquetípicas. $2^{\circ}$ Encontro dos Amigos da Psicologia Arquetípica: Clínicas Arquetípicas. (p. 111-122). São Francisco Xavier, SP.

Perrone, P. (2004). A clínica do social: escuta e alteridade. In III Congresso Lartino-Americano de Psicologia Analítica. (p. 321-325). Salvador, SP: Lector Editora.
} 